\title{
ENCUADRANDO EL DELITO: PÁNICO MORAL EN LOS PERIÓDICOS ARGENTINOS
}

\section{Framing crime: moral panic in Argentine newspapers}

\author{
Natalia ARUguete \\ Universidad Nacional de Quilmes, Argentina \\ \nataliaaruguete@gmail.com \\ Belén AMADEO \\ Universidad de Buenos Aires, Argentina \\ $\triangle$ belenamadeo@gmail.com
}

BIBLID [1130-2887 (2012) 62, 177-196]

Fecha de recepción: 12 de abril del 2012

Fecha de aceptación: 18 de julio del 2012

RESUMEN: El asalto a Carolina Píparo a la salida de un banco en la provincia de Buenos Aires, Argentina, estremeció a la opinión pública por tratarse de una víctima embarazada que, a raíz de un disparo recibido en el ataque, debió someterse a una cesárea después de la cual su hijo sobrevivió sólo una semana. Este trabajo analiza el tipo de tratamiento que recibió el llamado «caso Píparo» a través de un análisis de contenido exploratorio e inductivo de la cobertura que los diarios Clarín y La Nación dieron al tema. El objetivo es elaborar un libro de códigos que pueda ser validado en estudios de casos similares mediante el análisis de contenido de la prensa gráfica. Se busca aplicar la teoría del framing para, desde la detección de los encuadres noticiosos empleados, discutir si éstos son compatibles con el concepto de pánico moral planteado por Stanley Cohen.

Palabras clave: framing, pánico moral, inseguridad, medios de comunicación, Argentina.

ABSTRACT: Carolina Píparo was shot a few minutes after withdrawing cash from a bank branch. This case outraged the public opinion because she was eight months pregnant at the moment of the assault. She had to undergo a caesarean section and her baby only survived one week. Through an exploratory and inductive research we will analyze how the Argentine newspapers presented the case. We aim at elaborating a content analysis code book that can be validated in future similar researches on the subject. We apply the Framing theory in order to detect the frames used in the news coverage and to observe if they are compatible with the idea of «moral panic» proposed by Stanley Cohen.

Key words: Framing, moral panic, lack of safety, mass media, Argentina. 


\section{INTRODUCCIÓN ${ }^{1}$}

El 29 de julio de 2010, Carolina Píparo, embarazada de ocho meses, fue atacada junto a su madre a la salida de un banco en la ciudad de La Plata, Buenos Aires, Argentina. Una banda de asaltantes las siguió hasta su domicilio, donde las sorprendió. Carolina Píparo entregó el dinero de inmediato, pese a lo cual recibió un disparo de uno de los ladrones. Esa severa lesión obligó a una cesárea de urgencia. La mujer estuvo 42 días internada. Isidro, su bebé, no resistió y murió una semana después. El caso conmocionó a la opinión pública y la gente siguió este tema de cerca en todos los medios de comunicación.

Luego de este ataque, y en sólo dos meses, las autoridades provinciales y nacionales impulsaron modificaciones en los sistemas de seguridad bancarios. Exactamente dos meses después, el 29 de septiembre, el Congreso Nacional sancionó una ley por la cual los bancos debieron reforzar sus sistemas de seguridad de manera extrema. Entre el robo a Carolina Píparo y la sanción de la norma, los medios llevaron una cobertura diaria de la evolución de la víctima y dieron un extenso espacio a asaltos similares.

El objetivo de este trabajo es distinguir los rasgos sobresalientes de la cobertura mediática que recibió este caso en la prensa gráfica argentina, mediante un análisis de contenido exploratorio (Piñuel Raigada 2002). Aplicando la teoría del framing desde un abordaje inductivo (Igartua 2006; Igartua y Muñiz 2004; Semetko y Valkenburg 2000) será posible elaborar una serie de encuadres noticiosos que den cuenta del tipo de tratamiento que los diarios de mayor circulación de la Argentina, Clarín y La Nación, hicieron de lo que hemos dado en llamar «inseguridad bancaria». Se discute si los encuadres noticiosos detectados son compatibles con las características que Stanley Cohen (2009) atribuye al concepto de «pánico moral».

\section{MARCO TEÓRICO}

\section{II.1. Framing}

Shanto Iyengar y Donald R. Kinder buscaron responder de qué modo los medios afectan las perspectivas políticas de los públicos. El papel y la fuerza que éstos cobran en la política han sido debatidos durante años, pero los autores llegaron a la conclusión de que los medios influyen en la percepción pública no tanto por el hecho de mencionar asuntos delicados, sino por la forma en la que se los presenta (Iyengar y Kinder 1987).

La búsqueda por alcanzar una conceptualización de este término depende, en parte, de la instancia de comunicación que se procura indagar. Algunos autores entienden que el framing o los frames se dan en una única etapa, mientras que otros consideran

1. Las autoras agradecen los comentarios y las sugerencias de dos evaluadores anónimos de América Latina Hoy, Revista de Ciencias Sociales, a una primera versión de este artículo. 
que atraviesan todo el proceso comunicacional, en tanto pueden ser localizados en el comunicador, el texto, el receptor y la cultura (Entman 1993).

En cuanto a los objetivos de esta teoría, Amadeo sostiene que el framing aparece como una transferencia de significados que atraviesa las distintas etapas de la comunicación:

De este modo explica el vínculo entre el mensaje y su interpretación. La teoría del Framing estudia el proceso de transmisión de significados, signos, símbolos y valores de la sociedad a los medios y viceversa (Amadeo 2008: 185).

Teniendo esta definición de framing como supuesto teórico básico, y acordando con Cohen y Wolfsfeld en que los frames son principios de la organización de la información que se encuentran en el emisor, en los individuos receptores del discurso mediático y en las prácticas sociales y culturales (Cohen y Wolfsfeld 1993), en este trabajo se analizan los encuadres noticiosos, o news frames, que los medios dieron al tratamiento de la inseguridad bancaria en general y del caso Píparo en particular.

Entre las definiciones de frames que hacen foco en el proceso de elaboración de las noticias se encuentra la de Entman, para quien encuadrar es:

[...] seleccionar algunos aspectos de una realidad que se percibe y darles más relevancia en un texto comunicativo, de manera que se promueva una definición del problema determinado, una interpretación causal, una evaluación moral y/o una recomendación de tratamiento para el asunto descripto (Entman 1993: 52).

Este autor afirma que los encuadres noticiosos ofrecen perspectivas sobre el asunto tratado para interpretar la información. En otras palabras, encuadrar es definir problemas: diagnosticar sus causas o las fuerzas que lo crean, hacer juicios morales al evaluar el agente que lo causa, medir con qué costos y beneficios y sugerir soluciones, ofreciendo y justificando un tratamiento y prediciendo sus resultados.

Los frames son herramientas fundamentales para transmitir informaciones: aumentan las perspectivas, revelan entendimientos particulares sobre los eventos y terminan transformando la forma de pensar del público sobre un asunto. Proveyendo, repitiendo y reforzando palabras o imágenes que se refieren a ciertas ideas pero no a otras, los frames funcionan para dar más relevancia a ciertas ideas en los textos, menos a otras y volver completamente invisibles otras (Entman 1991: 7).

También Stephen Reese aportó una de las definiciones más completas de frame. «Son principios organizadores socialmente compartidos y persistentes en el tiempo, que trabajan simbólicamente para estructurar el mundo social de modo significativo» (Reese 2001: 11).

Los medios transforman las dimensiones de los acontecimientos en productos informativos que pasan por una serie de filtros hasta llegar a las audiencias [...]. Representan los acontecimientos pasándolos por el filtro del periodista, por sus rutinas profesionales y por la organización para la que trabajan (Sádaba 2008: 69). 
Es por ello que es importante traer aquí la idea de noticia como producto de creación subjetiva, ya que permite enfatizar el rasgo constructivista de esta teoría, plasmado en todas sus instancias de análisis: el proceso de elaboración del discurso informativo, las huellas dejadas en el texto y los efectos generados en las audiencias (Aruguete 2011a).

En cuanto a los rastros que los news frames dejan en los textos, Entman sugiere identificarlos a partir de «la presencia o ausencia de ciertas palabras clave, una serie de frases, imágenes estereotipadas, fuentes de información y oraciones que proveen grupos de hechos o juicios reforzados temáticamente» (Entman 1993: 52). Al presentar las noticias, los medios dejan traslucir un interés más dramático que fáctico (Bennett y Edelman 1985). En el mismo sentido, Protess et al. (1991) observan que los hábitos narrativos con los que el periodismo presenta a los personajes de una historia se estructuran en términos de buenos y malos, ganadores y perdedores, justos e injustos, problemas legales y soluciones institucionales.

Este rasgo de las coberturas es definido por Bennett como «personalización de las noticias» (Bennett 1983). Esto es, crear historias alrededor de los actores de los hechos, más que de los eventos en sí. Tal enfoque de las noticias puede ser interesante, asume el autor, pero oscurece las características más importantes de los acontecimientos. El efecto que este comportamiento tiene sobre la audiencia es que distorsiona su visión del poder, de las cuestiones y de sus consecuencias.

A partir de este tipo de tratamiento noticioso, Amadeo entiende que el análisis de los protagonistas de la información se vincula con la atribución de responsabilidades que pueda generar en el lector (Amadeo 1999). Si bien Iyengar no se refiere al encuadre de las noticias en términos de «personalización», desde otros dispositivos narrativos reconoce que las atribuciones de responsabilidad pueden ser individuales o institucionales/sociales. «Según cuánta relevancia le dé a los individuos o a las instituciones en la cobertura, el personaje quedará más o menos implicado y su prestigio se verá más o menos dañado» (Iyengar 1991: 263).

Otro elemento que permite analizar el caso Píparo es cómo se presentaron sus etapas en la cobertura noticiosa. Para ello se ha debido definir qué hechos marcaron puntos de inflexión en la historia, por qué llamaron la atención y si fueron realmente hitos destacados o construcciones de los medios de comunicación.

Según Brosius y Eps, los medios no sólo forman parte del proceso de atribución de sentido social, sino que tienen mayor peso que la sociedad en este terreno (Brosius y Eps 1995). Estos autores hablan de «eventos clave» (key events) al referirse a los acontecimientos sociales que necesitan de una mayor atención por parte de los medios. Los key events, prototipos de cobertura que poseen esquemas informativos establecidos, funcionan como estereotipos, provocando que los hechos similares tengan más probabilidad de ser seleccionados que otros (Sádaba 2008). Esto nos muestra que los acontecimientos pueden ser redefinidos (Amadeo 2008).

Los eventos clave enfrentan a los periodistas y al público con una situación desconocida, difícil de evaluar y clasificar. Son los periodistas quienes se hacen más sensibles al tema y buscan más información en agencias informativas y en fuentes escritas, 
discuten con colegas, leen artículos de otros medios y buscan más activamente otra información, investigan. Al final de esta etapa de orientación, los criterios nuevos o cambiados son usados para clasificar los eventos clave y los que le siguen (Brosius y Eps 1995).

Los frames dejan de ser un mero sistema de selección de temas noticiables. Con los avances de la investigación en comunicación, éstos se convierten en patrones persistentes de las mentes de quienes administran, dominan y manejan los símbolos sociales (Gitlin 1980: 7). Esto resalta la importancia de comprender cómo funciona el framing en el proceso de elaboración de la noticia.

\section{II.2. Pánico moral}

El sentimiento de inseguridad, sostiene Gabriel Kessler (Aruguete e Isaía 2011), es la sensación de indefensión que los individuos pueden tener ante una amenaza aleatoria. En otras palabras, el hecho de creer que cualquiera puede ser víctima de un delito sin poder preverlo ni evitarlo genera un gran malestar y una fuerte sensación de impotencia. Sin embargo, ese sentimiento de inseguridad mantiene una autonomía relativa respecto del delito efectivo (Kessler 2009). El hecho de que exista el delito no siempre genera ese sentimiento, al tiempo que sentirse inseguro no necesariamente se corresponde con las estadísticas de delito. Prueba de ello es que en 2004 en la Argentina, el nivel de delitos cometidos alcanzó el $22 \%$, mientras que la sensación de inseguridad llegó al 68,4\%. La diferencia entre ambas dimensiones se mantuvo hasta 2007, ubicándose en 27,3\% y 77,4\%, respectivamente (Moreno y Sigal 2009).

$\mathrm{El}$ «pánico moral», por otra parte, ya no supone una sensación de inseguridad individual sino colectiva. Es una construcción social que avala acciones correctivas en defensa de la comunidad. A comienzos de la década de 1970, Stanley Cohen acuñó el término y lo explicó de la siguiente manera:

De vez en cuando, las sociedades parecen estar sujetas a períodos de pánico moral. Ello supone que una condición, episodio, persona o grupo de personas emergen y son definidos como una amenaza para los valores e intereses sociales. Su naturaleza es presentada por los medios de comunicación de una forma estilizada y estereotipada, y las «barricadas morales» son tripuladas por editores mediáticos, obispos, políticos o incluso expertos sociales, todos ellos acreditados por la comunidad para pronunciar sus diagnósticos, soluciones y formas de afrontar el problema. A menudo, tiempo después, la condición desaparece, se sumerge o se deteriora. A veces, el objeto del pánico es novedoso. Otras veces, en cambio, se trata de algo que ha existido un tiempo antes, pero que irrumpe en el centro de atención en un momento dado. En algunas ocasiones el pánico sobrevuela y se olvida -excepto en el folklore y la memoria colectiva- pero en otras tiene repercusiones más graves, es de larga duración y podría producir cambios en el nivel político, jurídico y social, o incluso, en la forma en que la sociedad se concibe (citado en Hunt 1997: 630-631). 
Por ello, es oportuno mencionar los elementos que, según Cohen, constituyen el pánico moral:

1. preocupación -más que miedo- acerca de la amenaza potencial o imaginada;

2. hostilidad hacia los actores -«demonios populares»- que encarnan el problema y hacia los organismos públicos, que son los últimos responsables;

3. consenso, es decir, un acuerdo generalizado -no necesariamente total- de que la amenaza existe, es seria y «se debería hacer algo» al respecto. La mayoría de las élites y los grupos de influencia, especialmente los medios, deben compartir este consenso;

4. desproporción, esto es, una exageración del número o la magnitud de los casos, en términos del daño causado, la ofensa moral y el riesgo potencial, si se ignora. Consecuentemente, la preocupación pública no es directamente proporcional al daño objetivo; $y$

5. volatilidad, lo que significa que el pánico entra en erupción y se disipa de repente y sin previo aviso (Cohen 2009 [1972]).

En este punto, se puede distinguir el concepto de «sentimiento de inseguridad» de las ideas de «victimización» y de «pánico moral». Soto Navarro explica que el miedo al delito se puede definir como la percepción que tiene cada ciudadano de sus propias probabilidades de ser víctima de un delito. El miedo al delito no se relaciona con las posibilidades reales de ser víctima, esto es, no responde a causas objetivas y externas, por ende, la carga emotiva suele prevalecer (Soto Navarro 2005).

En este tipo de cobertura, la prensa otorga escaso protagonismo a expertos en temas político-criminales y más atención a grupos de presión, sindicatos policiales y funcionarios de prisiones, cuyas quejas y demandas pueden canalizar la solución del problema de la delincuencia en la dirección que más favorece a sus intereses profesionales (Soto Navarro 2005). Según Killias, la preocupación por el delito repercute de modo directo en las actitudes punitivas, de modo que, a mayor preocupación, mayores exigencias de amplitud e intensidad de intervención penal se puede encontrar en los medios (Soto Navarro 2005: 81).

Ahora bien, para Cohen se deben cumplir tres condiciones para que un caso de pánico moral sea exitoso: se necesita que haya un enemigo adecuado, esto es, con poco poder, escasa presencia en los medios, que sea fácilmente denunciable y que no cuente con legitimidad. Además, la víctima debe ser la correcta: alguien con quien uno pueda identificarse. Finalmente, se requiere generar un consenso acerca de que no se trata de un problema aislado sino de una problemática que compete a toda la sociedad, ya que puede pasar en cualquier lado (Cohen 2009 [1972]: 11).

Según este autor, en la década de 1960, el pánico moral y la amplificación de la desviación estaban simbióticamente unidos - por una relación causal- a las afirmaciones de los medios, a quienes se los consideraba la fuente primaria del conocimiento público acerca de tales problemas sociales. En este marco, la función de los medios se manifestaba en su capacidad de establecer la agenda, seleccionando aquellos eventos socialmente problemáticos que eran considerados de interés periodístico y decidiendo cuáles de tales acontecimientos serían candidatos para generar pánico moral. 
Esto supone que la exposición mediática ayuda al mismo desenlace moral, en tanto el crimen es retratado como una amenaza penetrante, no sólo para las víctimas vulnerables sino para la gente común en su vida cotidiana (Cohen 2009 [1972]).

En esta misma línea, Hall y sus colegas entienden que es apropiado hablar de los principios de un pánico moral cuando los medios enfatizan el «repentino y dramático» incremento del crimen -en el número de personas o de eventos implicados-y la «novedad», más allá de lo que una evaluación sobria y realista podría sostener (Hall et al. 1978: 16). Este mecanismo, definido por Fernández Pedemonte como «estrategia de tenaza», supone la selección de hechos violentos «fuertes» en función de su negatividad y novedad y su representación mediática como fenómeno anormal y fácilmente condenable (Fernández Pedemonte 2005).

En relación con el temor público, diversos investigadores ${ }^{2}$ plantean que no es la victimización directa sino la indirecta la que puede ocasionar mayores efectos en este sentido. Escuchar a gente conocida o a amigos que han sido víctimas de un delito puede generar mayor miedo al crimen que la propia experiencia. Y los medios de comunicación, sostiene Kessler (2005), son sin dudas la principal fuente de victimización indirecta.

En 1994, Goode y Ben-Yehuda establecieron distintos tipos de pánico moral: el ligado a «grupos de interés», el tramado por una coalición de «emprendedores morales» y el que surge «desde abajo» (citados en Hunt 1997: 629). Esta tipología contribuye a desenfocar el papel de los medios como promotores únicos y omnipotentes de pánico moral. Es que los periodistas:

Responden a ciertos criterios sociales y profesionales por medio de los cuales recogen y elaboran información que será plasmada en un texto que, a su vez, será leído, visto u oído, por receptores, que, posteriormente, reconocerán en este texto una noticia, interpretarán su contenido y actuarán siguiendo pautas interiorizadas (Amadeo 2008: 198).

\section{MÉTODO}

A fin de analizar cuánto énfasis pusieron los medios en la necesidad de implementar políticas públicas sobre esta cuestión y cómo describieron el desempeño de los actores políticos en este sentido, se inició un análisis de contenido exploratorio para conocer qué encuadres noticiosos utilizaron al abordar lo que dimos en llamar «inseguridad bancaria»y, en particular, el caso Píparo. Piñuel Raigada (2002: 8) afirma que el análisis de contenido exploratorio es «una aproximación al diseño definitivo de una investigación», mediante la cual se elaboran, registran y tratan datos sobre documentos ${ }^{3}$.

2. Ver, por ejemplo, S. Box, Ch. Hale y G. Andrews (1988); W. Slogan y M. Maxfield (1981), citados en G. KesSLER (2005: 20).

3. Para una exhaustiva descripción de las técnicas de análisis de contenido, cfr. J. J. IGARTUA, (2006); K. Krippendorff (2003); J. J. SÁnchez Aranda (2005); J. L. Piñuel Raigada (2002). 
Asimismo, se observó si el tema se centró en la evolución del caso o en sus actores, si los medios privilegiaron algún eje temático, si hicieron una cobertura más emocional que técnica o viceversa y a qué tipo de fuentes recurrieron. ¿Contextualizaron y tematizaron su cobertura o la redujeron a eventos dramáticos y fragmentados?, ¿propusieron soluciones a este problema de la inseguridad bancaria? Se buscó observar, por último, si el tratamiento noticioso en cuestión había tenido rasgos propios de lo que Stanley Cohen llama «pánico moral» (Cohen 2009 [1972]).

Para alcanzar el objetivo de este estudio, se propone elaborar un libro de códigos cuyo diseño se discute en este trabajo, buscando que esta matriz de análisis pueda ser validada en estudios posteriores que traten casos de inseguridad bancaria. Este pretest permitirá establecer las variables y categorías y la prueba de los indicadores de medida que den cuenta de la forma en que fue encuadrado mediáticamente el caso Píparo (Piñuel Raigada 2002), con el propósito de cuantificarlas en un análisis ulterior ${ }^{4}$.

Es posible analizar los encuadres noticiosos desde un acercamiento deductivo o inductivo. En este trabajo se opta por aplicar un abordaje inductivos: los textos son estudiados desde una perspectiva abierta, con preconcepciones vagamente definidas, ya que las variables surgen en la instancia del análisis (Igartua 2006; Semetko y Valkenburg 2000). Para la creación de las variables que conformarán el libro de códigos se parte de la noción de framing planteada por Entman (1993). Estos conceptos serán operacionalizados siguiendo la técnica para la elaboración de frames propuesta por Miller y Riechert (1994 y 2001), quienes observan que las palabras y expresiones clave constituyen un primer paso para la identificación de los encuadres noticiosos sobre un tema determinado. De allí surgirá la matriz de análisis que se desarrolla en el próximo apartado.

\section{III.1. Objetivos y preguntas de investigación}

El objetivo de este trabajo es realizar un análisis exploratorio de la cobertura del caso Píparo con el propósito de detectar los encuadres noticiosos empleados en el tratamiento que los medios dieron a este tema y discutir si éstos guardan relación con los rasgos de lo que Cohen (2009 [1972]) define como «pánico moral». Se procura que este índice de frames sea validado en estudios posteriores en los que se indague cómo la prensa gráfica encuadra casos semejantes a lo que hemos denominado «inseguridad bancaria».

4. Según J. L. PiÑuel Raigada (2002: 8), estos análisis se dirigen «a resolver los problemas relativos a la elaboración de las categorías más pertinentes que han de configurar un protocolo de análisis y su eventual articulación [...], de modo que resulten productivas de cara a la explotación de los datos».

5. Diversos autores diferencian entre abordajes deductivos e inductivos para la medición de los encuadres noticiosos (J. J. Igartua 2006; M. Miller y P. B. Riechert 2001; H. SemetKo y P. VALKENBURG 2000). 
Los objetivos específicos son cuatro:

1. Describir la relevancia que los medios dieron a este asunto en términos de frecuencia de publicación y de jerarquía noticiosa.

2. Establecer el comportamiento temporal de dicha relevancia informativa.

3. Indagar los encuadres noticiosos que surgen de la cobertura de la inseguridad bancaria y, en especial, del caso Píparo.

4. Discutir si los news frames creados a partir de este análisis guardan relación con la noción de «pánico moral».

De tales objetivos se desprenden una serie de hipótesis y preguntas de investigación:

H.1: la cobertura mediática del caso Píparo dio lugar a encuadres que amplificaron la presencia de ese hecho en los medios generando presión en los actores políticos para que se tomara alguna acción al respecto.

H.2: las etapas del caso fueron marcadas por hitos dentro de su cobertura. Algunos de estos hitos presentaron mayor interés para los medios, que le otorgan una cobertura más extendida.

P.1: ¿cuáles fueron los encuadres noticiosos que surgieron de la cobertura de la inseguridad bancaria, y, en especial, del caso Píparo?

P.2: los news frames creados, ¿guardan relación con el concepto de «pánico moral»?

\section{III.2. Unidad de análisis}

Una vez dentro del diseño de la investigación propiamente dicho, se tomaron como unidades de análisis todos los artículos que cubrían el caso Píparo en particular o cualquier delito relacionado con bancos dentro del lapso de dos meses entre el asalto y la sanción de la ley. Se incluyeron notas de todos los géneros y se revisaron todas las secciones de ambos diarios, con excepción de los suplementos especiales.

\section{III.3. Unidad de contexto}

Clarín es el principal diario argentino, nació en 1945 y es el de mayor circulación en el mundo de habla hispana (Albornoz 2006). Desde mediados de los años ochenta y con mayor intensidad durante la década de 1990, ha tenido un significativo crecimiento empresarial, a nivel horizontal, vertical y conglomeral (Becerra y Mastrini 2009). Su gran nivel de tirada ha sido determinante en su capacidad de fijar la agenda de temas en el público y en otros medios.

Creado en 1870, La Nación es uno de los diarios más antiguos del país. Su línea editorial pone de manifiesto una preocupación por mantener «los principios del liberalismo bien entendido, polifacético» (Ulanovsky 1997). En este sentido, si bien este matutino se caracterizó por la polifonía ideológica, nunca abandonó su filosofía liberal y tradicionalista. 


\section{III.4. Universo de análisis y muestra}

El universo de análisis está formado por las notas publicadas por los periódicos Clarín y La Nación, entre el 29 de julio de 2010, fecha del ataque a Carolina Píparo, y el 30 de septiembre de ese mismo año, cuando el Senado Nacional sancionó la Ley de seguridad bancaria. En total, se recabaron 445 artículos que cubren todo lo referido al caso Píparo y a lo que hemos denominado «inseguridad bancaria». Entendemos por inseguridad bancaria todo hecho delictivo derivado de las operaciones que los clientes hacen físicamente en la sucursal de la institución: salideras, asaltos, secuestros, agresiones o amenazas, y cuyas víctimas han sido elegidas en el banco por los agresores.

Al universo de artículos recabados se lo cuantificó para poder establecer la relevancia noticiosa que tuvo este caso a lo largo del período analizado. Posteriormente, se delimitó una muestra conformada por el $10 \%$ de las unidades ( 45 notas), sobre las que se realizó una inmersión cualitativa para la elaboración del libro de códigos (Igartua 2006; Miller y Riechert 1994, 2001).

\section{ANÁLISIS DE LOS PERIÓDICOS}

En esta instancia se exponen las bases sobre las que se sustenta la investigación y se desarrolla la matriz que ha surgido de nuestra aproximación exploratoria al corpus. En ulteriores investigaciones se contrastarán los resultados obtenidos de un análisis cuantitativo deductivo del universo completo, con encuestas de opinión realizadas al momento de la cobertura por consultoras de opinión pública y con entrevistas en profundidad a los redactores y editores de los periódicos en cuestión. Tales hallazgos permitirán comprender el proceso de framing en el marco de la cobertura de un caso de «inseguridad bancaria» en la Argentina.

El libro de códigos elaborado para el análisis de contenido está estructurado en una serie de etapas del «caso Píparo» y en los encuadres noticiosos de la cobertura.

\section{IV.1. Relevancia de la información}

Cuando hablamos de la noción de «relevancia» desde la teoría del framing se recurrió a diversos estudios que coinciden en entender que un modo de encuadrar es atribuir relevancia a un tema, es decir, dar prioridad a unos elementos sobre otros y hacerlos más fáciles de recordar (Amadeo 1999). Para dar una relevancia determinada a las noticias, los periodistas se valen de frames en el texto. Lo hacen, principalmente, por medio de la repetición del tema y de la ubicación en la cual presentan la noticia ${ }^{6}$ (ver Tabla I).

6. «La "relevancia" implica visibilidad y recuerdo de la información. Para lograr esto los medios cuentan con la ubicación de la noticia -arriba a la derecha, en página impar-, mayor tamaño, la disposición de la información con respecto a otras o una mayor frecuencia de cobertura del tema» (AMADEO 2008: 195). 
NATALIA ARUGUETE Y BELÉN AMADEO

ENCUADRANDO EL DELITO: PÁNICO MORAL EN LOS PERIÓDICOS ARGENTINOS

TABLA I

RELEVANCIA DE LA INFORMACIÓN SOBRE INSEGURIDAD BANCARIA

29 DE JULIO - 30 DE SEPTIEMBRE DE 2010

\begin{tabular}{cc}
\hline \multicolumn{2}{c}{ RELEVANCIA DE LA INFORMACIÓN } \\
\hline Importancia & Porcentaje \\
\hline Aparece en tapa & $29,2(\mathrm{~N}=130)$ \\
Página impar & $52,6(\mathrm{~N}=234)$ \\
Con imagen & $40,7(\mathrm{~N}=182)$ \\
Gran tamaño* & $13,9(\mathrm{~N}=62)$ \\
\hline
\end{tabular}

* Se considera que la nota tiene un «gran tamaño» cuando abarca más de $2 / 4$ de la página de un diario.

Fuente: Elaborado por el autor.

Una lectura de estos indicadores en forma desagregada muestra que el caso Píparo alcanzó una importancia noticiosa significativa, dado que casi un tercio de las unidades fue mencionada en tapa, más de la mitad apareció en página impar, cuatro de cada diez estuvieron acompañadas con alguna imagen (fotos, dibujos, infografías o gráficos) y arriba del $10 \%$ ocupó más de la mitad de la página. Ahora bien, los datos acumulados del análisis de contenido permiten sólo descripciones globales del tipo de cobertura, pero no dan razón del porqué de la misma. Para ello se requieren pautas de comparación (Amadeo 1999: 226). En este caso, el eje de comparación se apoya en la evolución que el discurso pudo haber sufrido en el transcurso temporal del caso, para lo cual éste fue dividido en etapas.

Dos fueron los objetivos que llevaron a la decisión de dividir el periodo de análisis en etapas. Se buscó, por un lado, explorar qué criterios son utilizados para convertir un evento en un acontecimiento noticiable y, por otro, analizar cómo evoluciona el comportamiento de los encuadres a lo largo del caso. Los hechos a los que los medios dieron más importancia marcarán el inicio de cada etapa.

En el caso Píparo, las etapas fueron marcadas por seis hitos relevantes en la historia: 1) el ataque en sí; 2) la muerte de Isidro; 3) la denuncia sobre los vínculos con la policía por parte de uno de los delincuentes; 4) la media sanción por la Cámara de Diputados al proyecto conocido como «ley de salideras bancarias», por el cual los bancos debían mejorar sensiblemente los factores de seguridad para las personas que están efectuando transacciones en los bancos; 5) la ratificación por parte del Poder Ejecutivo de medidas a favor de la bancarización; 6) la confirmación de la sanción de la Ley de Salideras Bancarias.

Estos hechos marcan etapas dentro del caso, que recibieron coberturas particulares por parte de los medios. Una comparación de éstas permite distinguir el grado de relevancia que los medios atribuyeron a la cobertura (ver Gráfico I). 


\section{GRÁFICO I}

RELEVANCIA DE LA INFORMACIÓN SOBRE EL CASO PÍPARO SEGÚN ETAPAS DEL CASO. 29 DE JULIO - 30 DE SEPTIEMBRE DE 2010

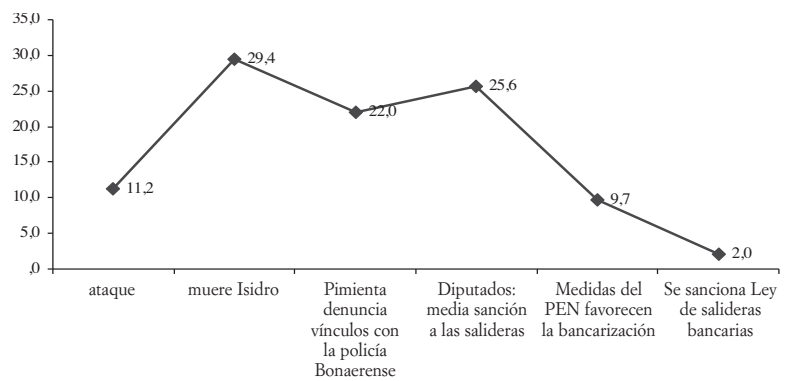

Fuente: Elaborado por el autor.

El gráfico evidencia que la etapa del caso que recibió mayor cobertura fue la muerte de Isidro, seguida por la media sanción a las salideras bancarias por parte de la Cámara de Diputados. En posteriores trabajos, donde se cuantifique el índice de encuadres noticiosos del caso Píparo creado en esta instancia, se pondrá en relación la relevancia de las etapas con los encuadres predominantes en las noticias, con el objeto de conocer si existe alguna regularidad empírica entre los tipos de eventos clave (key event) que cobran mayor importancia y la forma de encuadrar este tipo de acontecimientos.

\section{IV.2. Encuadres noticiosos}

Luego de analizada la relevancia informativa del caso Píparo, buscamos sus encuadres noticiosos y desarrollamos diez variables desde las cuales analizar las noticias con las que los medios presentaron el caso. Éstas darán lugar a siete posibles frames. Partimos de la definición de encuadres noticiosos de Igartua (2006: 157), como «constructos o variables latentes, no observables ni medibles directamente, sino que emergen a partir de una serie de indicadores manifiestos». La primera variable observa cómo se presenta a los protagonistas de la información, entendiendo que ello puede generar en el lector una atribución de responsabilidades. ¿A quién se da más importancia, a la víctima, al victimario o a las instituciones públicas? La cobertura, ¿se centra en el proceso o en los actores? Con estas preguntas como guía, la variable «protagonistas» quedó conformada de la siguiente manera: 
I. Protagonista de la nota

1. Poder Judicial o funcionario

2. Poder Ejecutivo Nacional o funcionario

3. Poder Ejecutivo Provincial o funcionario

4. Congreso nacional o provincial o funcionario

5. Funcionarios de la policía

6. Víctima Carolina Píparo

7. Víctima Isidro

8. Victimario

9. Familiares de la víctima

10. Familiares de los presuntos victimarios

11. Expertos que pertenecen a la estructura del Estado

12. Expertos que no pertenecen a la estructura del Estado

13. Otras víctimas

14. Otros delincuentes

15. Otros

La segunda variable está directamente relacionada con la primera y busca conocer la mirada desde la que se describió el eje temático de la información y cómo se diagnosticaron las causas del caso en cuestión.

II. Eje temático

1. Policial

2. Judicial

3. Político

4. Institucional

5. Social

6. Historia de vida

7. Otros

Coherente con ello, se analiza el «tono de la información» que primó en la nota, variable que se conformó como sigue:

III. Tono de la información

1. Puramente emocional

2. Predominantemente emocional

3. Combinado

4. Predominantemente técnico

5. Puramente técnico

6. Otros

Se entiende que esta variable estará en consonancia con el «eje temático» dominante en la cobertura. Es decir, que los artículos referidos a la salud de Carolina o la 
agonía de Isidro tendrán un componente fuertemente emocional, mientras que aquellas notas relativas a la contienda política tendrán un perfil técnico. Esto es así porque estos artículos buscarán vislumbrar sobre quién recaería la responsabilidad o quién se arrogaría la autoría de las propuestas legales frente a la problemática de la inseguridad bancaria.

La cuarta variable se pregunta si los «agentes que motivaron el problema» fueron encuadrados en términos individuales, sociales o institucionales. Con ello se procura indagar el grado de «personalización» (Bennett 1983) que se le dio a la cobertura. Así se operacionalizaron las causas del problema:

IV. Causas del problema o agentes que lo motivan

1. No se hace referencia a causas

2. Encuadre individual

3. Encuadre social

4. Encuadre institucional

5. Encuadre político/judicial

6. Otros

Además de definir problemas, el proceso de framing -en su instancia de elaboración de la noticia, en tanto que selección de ciertos aspectos de la realidad y ocultamiento de otros- tiene otro componente clave: su manejo de las «fuentes de información». Las fuentes predominantes en la información, computadas mediante el quinto indicador, proveen información respecto de la perspectiva desde la cual se diagnosticó el asunto y el tipo de soluciones que promovió el discurso mediático. El análisis deductivo medirá si los medios utilizan fuentes oficiales o extraoficiales, expertas o legas, ya sea en cuestiones de índole legal, médica, política o institucional. Esta variable se aplicará a las tres primeras fuentes citadas en los artículos. Se entiende que cada medio hizo un manejo particular de las fuentes. La consulta a familiares de las víctimas ratificaría la tendencia a la personalización de la cobertura del caso. Asimismo, entre las voces institucionales se haría hincapié en temas referidos a la investigación policial y no tanto a temas políticos o sociales. La variable «fuente» quedó estructurada de la siguiente manera:

\section{Fuentes}

0 . No se citan fuentes

1. Poder Judicial o funcionario

2. Poder Ejecutivo Nacional o funcionario

3. Poder Ejecutivo Provincial o funcionario

4. Congreso nacional o provincial o funcionario

5. Funcionarios de la policía

6. Víctima (Carolina Píparo)

7. Victimario (Ladrones)

8. Familiares de la víctima 
9. Familiares de los presuntos victimarios

10. Expertos que pertenecen a la estructura del Estado (peritos forenses, no se incluyen funcionarios públicos, aunque integren estructuras del Estado afines a temas de inseguridad)

11. Expertos que no pertenecen a la estructura del Estado (en esta categoría quedan incluidos los abogados y médicos vinculados al caso)

12. Trascendidos

13. Otros

En esta instancia se ha propuesto vislumbrar si, frente a la problemática desplegada en la información, además de diagnosticar causas, los medios proponen soluciones. La idea de crear las variables «causas del problema» y «soluciones» se inspiró en el concepto de Iyengar (1991), quien reconoce que las atribuciones de responsabilidad pueden ser expresadas en términos individuales o disposicionales (motivaciones, habilidades, entre otros) o en consideraciones estructurales (políticas de gobierno, condiciones económicas, entre otros), y encuentra que ello es consistente con las reacciones de los receptores de tales mensajes, esto es, cómo repercute el tipo de salidas que se proponen, tanto desde la sociedad como desde el poder político. En este análisis se espera ver una incipiente asociación entre las notas que tuvieron como protagonistas a los victimarios y un encuadre individual a la hora de apuntar a las causas del problema.

VI. Soluciones que se proponen para enfrentar el problema

1. No se habla de soluciones

2. Se propone una salida al problema de la inseguridad con política de mano dura

3. Se propone una salida al problema de la inseguridad con política de contención social

4. Se proponen soluciones relativas a la «seguridad bancaria»

5. No se ve salida posible

6. Otros

La siguiente variable busca medir si la información estadística es adecuada y relevante y, asimismo, si sirve para respaldar y legitimar la información o para aumentar el nivel de temor. En este sentido, la publicación de información estadística es clave, sobre todo si no son datos sólidos o si están enfocados de modo poco objetivo, con la intención de forzar una tendencia que «evidencia» el crecimiento de los niveles de delitos e inseguridad.

VII. ¿Se citan datos estadísticos?

1. NO

2. SÍ, indican aumento de la tasa de delito

3. SÍ, indican aumento de la tasa de victimización

4. SÍ, indican aumento de la tasa de inseguridad 
5. SÍ, indican disminución de la tasa de delito

6. SÍ, indican disminución de la tasa de victimización

7. SÍ, indican disminución de la tasa de inseguridad

8. Otros

El análisis de las noticias en términos de «dramatización» nos permitirá definir si la información está relatada en términos episódicos (instancias concretas o eventos definidos) o temáticos (es decir, enmarcados en un contexto más abstracto, como cambios en acciones políticas, la acumulación de un proceso de justicia criminal, entre otros). Se considera que la cobertura del caso pondrá énfasis en aspectos dramáticos, viscerales, espectaculares y personalizables, como se ha corroborado en estudios anteriores (García Beaudoux y D'Adamo 2007), a través del uso de un encuadre episódico que cree una trama asimilable a una novela policial, donde fácilmente se pueda reconocer a los buenos y los malos. Asimismo, se prevé que en aquellos casos en que se recurra al frame temático, con una mirada más analítica y con referencias a aspectos más abstractos, los temas colaterales a los que se asocie la noticia serán la «inseguridad», «las actitudes de los Poderes Ejecutivos Nacional y Provincial» o a la «Justicia», más que a la «situación social». Para corroborar tales presunciones, elaboramos los siguientes indicadores:

VIII. Dramatización

1. Episódico

2. Temático

IX. Temas colaterales con los que se relaciona expresamente el artículo (sólo para quienes respondieron 2 en la variable «Dramatización»)

1. Inseguridad/otros delitos (se incluyen las referencias a la «inseguridad bancaria»)

2. Actitud del Poder Ejecutivo Nacional

3. Actitud del Gobierno de la Provincia de Buenos Aires

4. Actitud de otros poderes del Estado

5. Situación de la sociedad

6. Legalidad

7. Otros

Además de estos dos encuadres, el tipo de contextualización que se hizo de los acontecimientos permite comprender qué tipo de relato recae sobre este fenómeno: fragmentado o histórico. La dramatización suele ir acompañada de una escasa contextualización de la información, y se tiene la hipótesis de que este caso seguirá esta tendencia. Con el objeto de constatar tal comportamiento se analiza si las noticias se limitan a contar un evento sin contextualizarlo o si, por el contrario, lo insertan en un marco histórico más amplio. 


\section{Contexto}

1. Fragmentado: Se limita a contar un evento sin contextualizarlo

2. Histórico: Incluye al tema en un marco histórico más amplio

Una vez definidas las variables para el análisis de contenido, las sistematizamos con el objeto de indagar si pueden ser articuladas con el concepto de «pánico moral» de Cohen.

\section{Discusión}

En este apartado se expone una serie de inferencias que surge del trabajo exploratorio realizado, con el objeto de vislumbrar si el caso Píparo dio lugar a una cobertura tendiente a generar pánico moral, entendiendo este concepto en términos de Cohen (2009 [1972]). La idea es, por lo tanto, plantear un vínculo entre los elementos que según Cohen constituyen el pánico moral ${ }^{7}$ y las variables que detectamos en la cobertura noticiosa.

En primer lugar, la preocupación acerca de la amenaza planteada por Cohen podría analizarse a través de las variables II, III y VII del análisis de contenido. Desde esta perspectiva se busca saber si el eje temático de la información es policial, judicial, político o institucional, cómo se definieron las causas del caso y si se utilizó un tono emocional o técnico en su cobertura. Asimismo, en esta instancia nos resulta interesante analizar si el uso de información estadística es correcto y si respalda o sesga la información.

En segundo término, el pánico moral refuerza la hostilidad hacia los presuntos responsables y hacia los organismos públicos que no cuidan a la población como corresponde. Las variables I y IV pueden acompañar esta característica del pánico moral. De este modo se puede analizar cómo se presenta a los protagonistas de los casos y cuál es el grado de personalización que se le dio a la cobertura.

La tercera característica del pánico moral es el consenso acerca de que la amenaza es seria y que la sociedad debe proveer algún tipo de solución al respecto. La cobertura mediática puede compatibilizarse con esto desde las variables V y VI propuestas en este trabajo: la perspectiva desde la que se elaboró el diagnóstico y el tipo de soluciones propuestos para el caso.

La cuarta propiedad del pánico moral -la desproporción o sobredimensionamiento de la cantidad o intensidad del daño causado- puede traducirse en la variable VII, que es la que evalúa el manejo de los datos empíricos utilizados por los medios para observar hasta qué punto el texto se ciñe a datos concretos o se vale de ellos para agigantar la historia.

La quinta y última característica del pánico moral es la volatilidad, analizable a través del séptimo encuadre, que es aquel que nos permite detectar si la información es dramatizada o tematizada por los medios, y si su cobertura se hizo de manera fragmentada o histórica. Esto es analizable a través de las variables VIII, IX y X.

7. Propuestos en el epígrafe 2.2. de este trabajo. 
Sistematizadas las variables se pueden definir cuáles fueron los encuadres noticiosos utilizados para cubrir la información sobre inseguridad bancaria durante el llamado «caso Píparo». Los frames noticiosos nos proveen de una herramienta conceptual y operativa para analizar el tipo de cobertura que tiene -en este caso- la «inseguridad bancaria».

Hecho el pretest, se considera que cada variable dará lugar a un frame independiente, con la excepción de las variables II y III -que, combinadas, intentarán captar la mirada desde la que se describe el eje temático de la información, cómo se diagnostican las causas y cuál es el tono que prima en la nota- y las variables VIII, IX y X, que en conjunto permitirán analizar qué enfoque global le dan los medios a la cobertura sobre la inseguridad bancaria.

Proveyendo, repitiendo y reforzando palabras o imágenes que se refieren a ciertas ideas y no a otras, los frames funcionan para dar más relevancia en los textos a algunos conceptos, menos a otros y volver completamente invisibles a otros más (Entman 1993).

De este modo, los frames, «modelos de cognición, interpretación y presentación» (Gitlin 1980), sirven a los productores de noticias en su manejo rutinario del discurso. Éstos, a su vez, están inmersos en una sociedad en la que participan activamente y en la que cuentan con valores propios y distintivos. En el caso que aquí nos ocupa, y por tratase de un tema tan delicado, entendemos que puede ser interesante crear una matriz de encuadres para acceder a las dimensiones subyacentes del discurso noticioso (Miller y Riechert 2001). Se considera que el «problema de la inseguridad»-issue que desde hace ya varios años se ha instalado como una de las principales preocupaciones de la sociedad argentina- está fuertemente validado por la cobertura que los medios otorgan a este tipo de acontecimientos. Y es precisamente en el marco de esta discusión donde vemos que tiene asidero analizar qué grado de actualidad ha recuperado el concepto de pánico moral acuñado en la década de 1970.

El propósito original de este trabajo fue crear una serie de encuadres basados en el concepto de framing de Entman (1993) para mostrar -en una posterior instancia de cuantificación deductiva- el modo en que los periódicos argentinos tratan los hechos delictivos como noticias. Paralelamente se buscó establecer en qué medida los frames recurrentes en este tipo de cobertura se articulan con los rasgos centrales que Cohen otorga al concepto de «pánico moral». Una vez propuesta esta relación entre el concepto de pánico moral y los encuadres operacionalizados en este trabajo, sólo resta realizar el trabajo empírico completo, con la esperanza de que esta matriz pueda ser validada en trabajos posteriores referidos a inseguridad.

\section{Bibliografía}

Albornoz, Luis. Periodismo Digital. Los grandes diarios en la red. Buenos Aires: La Crujía, 2006. AMADEO, Belén. La aplicación de la teoría del framing a la cobertura de la corrupción política en Argentina. 1991-1996. Tesis doctoral inédita. Pamplona, Facultad de Comunicación, Universidad de Navarra, España, 1999. 
Amadeo, Belén. Framing: Modelo para armar. En Baquerín Riccitelli, María Teresa (ed.). Los medios ¿aliados o enemigos del público? Derivaciones de las teorías de la comunicación surgidas en los setenta. Buenos Aires: EDUCA, 2008: 183-237.

ARuguete, Natalia. Framing. La perspectiva de las noticias. La Trama de la Comunicación, 2011a, vol. 15: 67-80.

ARUguete, Natalia e IsAíA, Walter. La relación entre percepción de inseguridad y delito efectivo es el doble. Diario Página 12. Buenos Aires, 23 de agosto de 2010. Consultado el 28 de mayo de 2011. http: //www.pagina12.com.ar/diario/dialogos/21-151840-2010-08-23.html.

BECERRA, Martín y MASTRINI, Guillermo. Los dueños de la palabra. Acceso, estructura y concentración de los medios en la América Latina del siglo XXI. Buenos Aires: Prometeo, 2009.

BenNetT, Walter L. News. The Politics of Illusion. New York: Longman, 1983.

BennetT, Walter L. y Edelman, Murray. Toward a new Political Narrative. Journal of Communication, 1985, vol. 35 (4): 156-171.

Brosius, Hans-Bernd y EpS, Peter. Prototyping through Key Events. European Journal of Communication, 1995, vol. 10 (3): 391-412.

Cohen, Akiba A. y WolfsFeld, Gadi. Framing the Intifada. People and the Media. Norwood, New Jersey: Ablex Publishing Corporation, 1993.

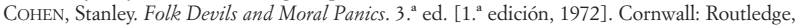
2009.

EnTman, Robert. Framing Us. Coverage of International News: Contrasts in Narratives of the KAL and Iran Air Incidents. Journal of Communication, 1991, vol. 41 (4): 6-27.

Entman, Robert. Framing: Toward Clarification of a Fractured Paradigm. Journal of Communication, 1993, vol. 43 (4): 51-58.

Fernández Pedemonte, Damián. Las olas de violencia y el conflicto de las agendas públicas. Oficios Terrestres, 2005, vol. 5: 27-37.

García Beaudoux, Virginia y D'Adamo, Orlando. Tratamiento del delito y la violencia en la prensa. Sus posibles efectos sobre la opinión pública. En LuCHEsSI, L. y RodRíGuEZ, M. G. (coords.). Fronteras globales. Cultura. Política y medios de comunicación. Buenos Aires: La Cruía, 2007: 169-185.

Grtuin, Todd. The Whole World is Watching. Berkeley: University of California Press, 1980.

Hall, Stuart; Critcher, Charles; Jefferson, Tony; Clarke, John y Roberts, Brian. Policing the Crisis: Mugging, The State, and Law and Order. London: Macmillan, 1978.

Hunt, Arnold. Moral Panic' and Moral Language in the Media. The British Journal of Sociology, 1997, vol. 48: (4) 629-648.

IgaRtuA, Juan José. Métodos cuantitativos de investigación en comunicación. Barcelona: Bosch, 2006.

IgARTUA, Juan José y MuÑIZ, Carlos. Encuadres noticiosos e inmigración. Un análisis de contenido de la prensa y televisión españolas. Zer. Revista de Estudios de Comunicación, 2004, vol. 16: $87-104$.

IYENGAR, Shanto. Is Anyone Responsible? (How TV frames political issues). Chicago: University of Chicago Press, 1991.

Iyengar, Shanto y KINDER, David R. News that Matters. Chicago: The University of Chicago Press, 1987.

KESSLER, Gabriel. Miedo al crimen: campo de investigación y preocupación política. Oficios Terrestres, 2005, vol. 17: 22-37.

KESSLER, Gabriel. El sentimiento de inseguridad. Sociología del temor al delito. Buenos Aires: Siglo XXI, 2009. 
KRIPPENDORFF, Klaus. Content Analysis: An Introduction to Its Methodology. 2. ${ }^{\text {a }}$ ed. [1. ${ }^{\text {a }}$ edición, 1980]. Newbury Park: CA, Sage, 2003.

MilLER, Mark M. y RIECHERT, Parnell B. Identifying themes via concept mapping: A new method of content analysis. Comunicación presentada en la Reunión Annual de la Association for Education in Journalism and Mass Communication. Atlanta, Estados Unidos, agosto 1994.

MiLLER, Mark M. y RIECHERT, Parnell B. The spiral of opportunity and frame resonance. Mapping the issue cycle in news and public discourse. En REESE, S. D.; Gandy, O. H. y Grant, A. E. (eds.). Framing public life. Perspectives on media and our understanding of the social world. Mahwah, NJ: Lawrence Erlbaum Associates, 2001: 107-121.

MoRENO, Carolina y SigAL, Ariel. El problema del delito en la Argentina: una mirada sobre la delincuencia, la violencia y el sentimiento de inseguridad. En Observatorio de la Deuda Social Argentina. Buenos Aires. Universidad Católica Argentina, 2009.

Piñuel Raigada, José Luis. Epistemología, metodología y técnicas del análisis de contenido. Estudios de Sociolingüística, 2002, vol. 3(1): 1-42.

PROTESs, D. et al. The Journalism of Outrage. Investigative Reporting and Agenda Building in America. New York: Guilford, 1991.

ReESE, Stephen D. Prólogo. Framing public life: A bridging model for media research. En REESE, S. D.; Gandy, O. H. y Grant, A. E. (eds.). Framing public life. Perspectives on media and our understanding of the social world. Mahwah, New York: Lawrence Erlbaum Associates, 2001: 83-94.

SÁDABA, Teresa. Framing: el encuadre de las noticias. El binomio terrorismo-medios. Buenos Aires: La Crujía, 2008.

SÁnCHez Aranda, José J. Análisis de contenido cuantitativo de medios. En Berganza Conde, María Rosa y SAN ROMÁn, José A. Investigar en Comunicación. Madrid: McGraw Hill, 2005: 207-228.

SemetKo, Holli y Valkenburg, Patti. Framing European politics: a content analysis of press and television news. Journal of Communication, 2000, vol. 50 (2): 93-109.

Soto NAvArRo, Susana. La delincuencia en la agenda mediática. Reis, 2005, vol. 112 (5): 75-130.

UlanOVSKY, Carlos. Paren las rotativas. Historia de los grandes diarios, revistas y periodistas argentinos. Buenos Aires: Espasa Calpe Argentina, 1997. 